\title{
HUIDOBRO EN ESPAÑA
}

Me propongo en el presente trabajo contribuir al esclarecimiento de algunos aspectos de la biografía de Vicente Huidobro y de la historia literaria española e hispanoamericana: los relacionados con los viajes del poeta a Madrid entre 1916 y 1921.

Huidobro llega por primera vez a Madrid en 1916. Así lo testimonian Gerardo Diego y Rafael Cansinos-Asséns.

Cansinos-Asséns, en Poetas y prosistas del novecientos, libro publicado en 1919, recuerda conversaciones mantenidas con Huidobro cuando visitó España, a fines de 1916, camino de París y procedente de la Argentina. La semejanza entre Las pagodas ocultas, de Huidobro, y El candelabro de los siete brazos, de Cansinos, ambos libros de 1914, fue tema de algunas de estas conversaciones amistosas, precedidas de un intercambio epistolar desde Chile ${ }^{1}$.

Durante esta visita asistió Huidobro, juntamente con Cansinos, a la tertulia que reunía sábado a sábado Ramón Gómez de la Serna en el Café de Pombo. Dice Cansinos en La nueva literatura: «Por aquella época, su país le envió a Francia agregado a la legación de Chile. Pasó por Madrid; se asomó a la cripta de Pombo y a nuestro diván de poetas jóvenes. Pero ninguna enunciación nos hizo de sus nuevas veleidades líricas...»².

En Poetas y prosistas del novecientos rememora también Casinos que Huidobro llevaba «en este viaje como viático lírico su último libro -Adán-.... ${ }^{3}$. No hace, en cambio, ninguna alusión a El espejo de agua, lo cual nos permite deducir que - si esta edición había ya apare-

${ }^{1}$ Rafael Cansinos-Asséns, "Vicente Huidobro", Poetas y prosistas del novecien. tos (España y América) (Madrid: América, 1919), pp. 107-108.

${ }^{2}$ Rafael Cansinos-Asséns, La nueva literatura, vol. III: La evolución de la poesía (1917-1927) (Madrid: Páez, 1927), pp. 198-199.

${ }^{3}$ Poetas y prosistas..., p. 110. 
cido en Buenos Aires o estaba en prensa- el poeta chileno no la difundió en Madrid en este primer viaje.

Gerardo Diego, en un artículo conmemorativo escrito en 1948, alude a «su primera aparición legendaria - Huidobro adolescente, y ya con mujer, hijos, un negrito y millones, se decía por la pobretería de las tertulias cafeteriles de madrugada-, allá por el año 1916, cuando apenas alboreaba la consigna creacionista entre el verdor de sus primeros libros». Y añade más adelante: «... la (visita) de 1918, ya con el creacionismo flamante..., fue la decisiva. Pocos meses después, y como consecuencia, nacía el ultraísmo y se armaba en España la que se armó...» ${ }^{4}$.

Llegamos así al segundo y más importante viaje de Huidobro a España.

Cansinos considera, en La nueva literatura, que el tránsito del poeta chileno por Madrid, procedente de París, en el otoño de 1918 - de agosto a noviembre-, constituye el acontecimiento literario supremo de ese año: «... a esa circunstancia debemos la anticipación de doctrinas estéticas, tan interesantes que por la vía callada del libro no hubiesen tenido el valor emocional del proselitismo que la presencia de uno de sus colaboradores le infundió...» ${ }^{5}$. Y explica: «Huidobro nos traía primicias completamente nuevas, nombres nuevos, obras nuevas; un ultramodernismo» ${ }^{6}$. Análogos testimonios dan Guillermo de Torre y César González-Ruano» ${ }^{7}$.

Huidobro volvió a España en otras oportunidades. David Bary, con la colaboración de Roger Utt, rescató de La correspondencia de España del 24 de noviembre de 1919 una nota de Cansinos-Asséns, que testimo-

4 Gerardo Diego, «Vicente Huidobro», tirada aparte de la Revista de Indias, 33-34 (julio-diciembre 1948), p. 1175.

${ }^{5}$ La nueva literatura, p. 200.

6 Ibid., p. 196.

${ }^{7}$ Dice G. de Torre: «De boca de Huidobro oí algunos de los primeros nombres verdaderos que iban a definir la época amaneciente; en su casa vi los primeros libros y revistas de las escuelas que luego darian tan pródigas y discutidas cosechas...» (Guillaume Apollinaire. Estudio preliminar y páginas escogidas [Buenos Aires: Poseidón, 1946], pp. 19-20).

César González-Ruano recuerda que conoció a Huidobro en ese viaje de 1918: «Cansinos nos lo presentó a los jóvenes como una especie de Mesías de una nueva era literaria...». Alude luego a la labor de difusión realizada por Huidobro: «Aquella tarde del Ateneo Huidobro vino ... con algún número de L'Élan y de Nord-Surd, en el que había poemas suyos, con otros de Breton, Aragon, Max Jacob, Tzara, etc.» (Veintidós retratos de escritores hispanoamericanos [Madrid: Cultura Hispánica, 1952], pp. 71-72). 
nia otra visita del poeta chileno por esa fecha. E1 valor fundamental de la nota reside, según lo destaca Bary, en el hecho de que Cansinos da cuenta de la existencia del inédito Voyage en parachute, que llevaba consigo Huidobro en este viaje ${ }^{8}$.

Un comentario de la revista Grecia nos permite deducir que realizó otro viaje entre agosto y septiembre de 1920 con el objeto de refutar los conceptos de Gómez Carrillo aparecidos en El Liberal, que atribuían la paternidad del creacionismo de Reverdy. El estilo del artículo y la actitud agresiva - por momentos petulante e inmadura- evidencian que ya han surgido los primeros desentendimientos entre el chileno y los ultraístas (o algunos de ellos).

El anónimo comentarista plantea dos problemas: el de la relación del creacionismo con el cubismo de Reverdy y el de la relación del creacionismo con el ultraísmo. En el primer caso recuerda que en 1918 Huidobro reconoció su deuda con Reverdy. En el segundo, refuta la afirmación del chileno, según la cual el ultraísmo es una degeneración del creacionismo. Termina declarando la ruptura de vínculos de los ultraístas con el poeta a quien apoda: "Huidobro el Ególatra» ${ }^{9}$.

- David Bary, «Sobre los orígenes de Altazor», ponencia presentada en el simposio sobre Vicente Huidobro y la vanguardia, Chicago, 6 de abril de 1978. La citada nota de Cansinos aparece consignada por N. Hey, «Bibliografía de y sobre Vicente Huidobro», Revista Iberoamericana, XLI, 91 (abril-junio 1975), p. 344, núm. 445.

«Panorama ultraísta», Grecia, 48 (21 septiembre 1920), p. 15. Sin firma. ¿Guillermo de Torre? El texto del artículo es el siguiente:

«Hace pocos días ha estado en Madrid el poeta americano Vicente Huidobro.

Según nos comunicó, su viaje a España tenía por principal objeto refutar un artículo de Gómez Carrillo publicado últimamente en El Liberal, en donde el citado cronista atribuía a Reverdy la paternidad del creacionismo.

En una actitud plañente, Huidobro en esos días recorrió las redacciones de los diarios más importantes para que le publicasen las cuartillas en donde de una manera violentísima y con una sintaxis ambigua replicaba a Gómez Carrillo, cosa que no pudo alcanzar.

$\mathrm{Y}$ como último recurso sólo consiguió que en $E l$ Liberal, y en una carta por él firmada, dijera que rechazaba las alusiones del artículo de referencia, al mismo ticmpo que anunciaba contestar ampliamente en las páginas de esta Revista.

Sin apetecerlas, nuestro director recibió, de mano de Huidobro, las desdichadas cuartillas, que nosotros también dejamos de publicar por no estar conformes con aquello que ahora pretende modificar, diciendo que él es el único inventor del creacionismo, cuando en el año 1918 nos dijo 'que al asistir en París a una lectura de poemas de Reverdy, reconoció en éste, casi lograda, la estética creacionista, que desde hacía algún tiempo andaba en su persecución'.

Además, el creacionismo de Huidobro es considerado en Francia como un brote del ultraísmo castellano, así lo ha manifestado últimamente el eminente crítico y 
En 1921 vuelve Huidobro a España para pronunciar una conferencia en el Ateneo de Madrid. Hemos encontrado una crónica en la revista Ultra (Madrid: 20, 15 diciembre 1921). Por ella sabemos que la conferencia tuvo lugar un día lunes de esa primera quincena del mes, bajo el título «Estética moderna». Huidobro fue presentado por Mauricio Bacarisse, quien simpatizaba con estos intentos renovadores.

Según el anónimo cronista de Ultra, la primera parte de la conferencia había sido publicada ya en L'Esprit Nouveau (París: abril 1921) y glosada por Guillermo de Torre en Cosmópolis ${ }^{10}$. Reseña Ultra:

Vicente Huidobro nos habló primero del arte en sus tres etapas sucesivas: arte reproductivo o inferior al medio, arte de adaptación al medio y arte superior al medio, o el que corresponde a la modalidad creacionista, adoptada por él.

La mayor parte, lo esencial de los postulados huidobrianos es lo que constituye el patrimonio de todo el arte nuevo, desde Apollinaire y Reverdy hasta las últimas exploraciones estéticas. En eso coinciden unos y otros y no comprendemos la causa por la cual el señor Huidobro se atribuye exclusivamente lo que es una característica y una aspiración común...

Después de esta digresión que niega la originalidad huidobriana, retoma el autor su función de cronista:

Luego aludió a los dadaístas, calificándolos de sepultureros.

Ellos -añadió- destruyen por el placer de destruir, y nosotros construimos por el placer de construir...

poeta Nicolás Beauduin, y en nuestro poder tenemos cartas de Huidobro en las que éste afirma que los ultraístas superamos a los modernos poetas franceses.

Pero he aquí que ahora Huidobro, egoístamente, piensa lo contrario diciendo en un artículo, en que se ocupa del movimiento literario hispanoamericano, en el L'Esprit Nouveau, que el ultraísmo es una degeneración del creacionismo.

Vean nuestros lectores y amigos la manera de corresponder de Huidobro a las excesivas consideraciones y elogios que desde estas coltumnas se le han atribuido.

En consecuencia, los ultraístas rompemos toda clase de vínculos con este poeta improvisado, que desde hoy denominaremos con el sobrenombre de "Huidobro el Ególatra'».

${ }_{10}$ Fue incluida, además, como prólogo a Saisons choisies (París: La Cible, 1921) bajo el título de «La création pure...». En las Obras completas de Huidobro, con el título "La poesía», se recoge otro texto como fragmento de esta conferencia (Cf. ed. Santiago de Chile: A. Bello, 1976, vol. I, p. 716). Cabe preguntarse la razón de esta diferencia. Tal vez constituya una segunda parte de aquella exposición. 
Finalmente admite el articulista que, aunque no comparta las teorías de Huidobro, es éste un poeta con méritos y personalidad; y concluye:

Vicente Huidobro está en nuestro mismo plano, a pesar de las diferenciaciones que nos distinguen..., y hoy, como ayer, son para él todo nuestro respeto y toda nuestra estimación.

La actitud ambigua del comentarista, que niega la originalidad de Huidobro pero admite sus méritos, y que - al afirmar la igualdad de planos - rechaza una relación discipular de los ultraístas con respecto al chileno, denotan — si no la autoría - al menos la influencia de Guillermo de Torre.

Este documento coincide con lo recordado por Juan Larrea: en aquella reunión del Ateneo, él y Gerardo Diego advirtieron cierta atmósfera de hostilidad de los ultraístas hacia Huidobro ${ }^{11}$.

\section{CREACIONISMO Y Ultraísmo}

Como se desprende de los testimonios anteriormente citados, cuando Huidobro visita Madrid en 1918, da a conocer sus inquietudes vanguardistas, sus teorías estéticas creacionistas y los libros que las encarnan (particularmente Horizon Carré, París, 1917, y los cuatro que editó en Madrid en 1918: Ecuatorial, Poemas árticos, Hallali y Tour Eiffel). Al mismo tiempo difunde otros nombres, libros y revistas de los movimientos vanguardistas europeos, relaciona a los españoles con los artistas plásticos extranjeros que residían en Madrid como consecuencia de la primera guerra, da datos bibliográficos o señas personales para establecer correspondencia con otros escritores europeos.

Huidobro parte en noviembre, y en diciembre, Cansinos-Asséns - estimulado por los aportes del chileno-, en una de sus tertulias del café Colonial, exhorta a un grupo de poetas jóvenes a constituir un movimiento de renovación literaria. Como resultado se publica el primer manifiesto ultraísta y a comienzos de 1919 encontramos ya al ultraísmo como grupo, como intención colectiva.

Es innegable la influencia que Huidobro tuvo sobre Cansinos, quien actuó como eje y promotor del nuevo movimiento. Es innegable también que la breve visita del chileno había preparado el terreno y mar-

${ }^{11}$ Juan Larrea, «Sobre Vicente Huidobro y la vanguardia», conferencia pronunciada en el Simposio citado, 6 abril 1978. 
cado pautas para los jóvenes que en torno a Cansinos y a través de las revistas del ultraísmo, se adhieren a las vanguardias literarias.

Pero es necesario decir que, si bien el creacionismo constituye el cauce principal del cual se nutre el ultraísmo, ambas no pueden identificarse.

Una simple mirada a las revistas del movimiento, o vinculadas con él, demuestra que acogían y difundían a las más diversas tendencias y autores extranjeros, ya fueran precursores o representantes del vanguardismo ${ }^{12}$. El ultraísmo es, pues, un movimiento abierto a todo lo nuevo, que asimila también influjos futuristas, cubistas, dadaístas, expresionistas...

\section{HUIDOBRO EN LAS REVISTAS ESPAÑOLAS}

Cuando Huidobro difunde su obra en Madrid en 1918, los comentaristas de la prensa le son, por lo general, adversos. Luis Astrana Marín, por ejemplo, lo zahiere en un artículo titulado «Las escuelas literarias. Ultraístas y creacionistas. La desaprensión de Vicente Huidobro» ${ }^{13}$.

A reacciones como ésta debió de referirse Gerardo Diego al afirmar: «En España entonces no se le comprendió muy bien, y de ello pueden dar fe los escritos en que se daba cuenta de su obra, por no hablar ya de las necedades que, tomando por las hojas el rábano de la poesía, emitían en tertulias, redacciones y domicilios ciertos santones del poema y del artículo crítico» ${ }^{14}$.

Muy distinto es el trato que recibe en las revistas vinculadas con el ultraísmo, que publican sus poemas y comentan sus teorías y obras. La actitud amistosa y laudatoria comienza a agriarse a partir de septiembre de 1920, probablemente como consecuencia de los primeros choques entre Huidobro y Guillermo de Torre.

Huidobro publica en Grecia y en Cervantes. Aparece por primera vez un poema suyo en el número 7 de Grecia (Sevilla: 15 enero 1919), página 5 , es decir, en los albores del movimiento y cuando esta revista

${ }^{12}$ Asi encontramos, juntamente con poemas de Huidobro, traducciones, glosas y estudios críticos sobre Mallarmé, Rimbaud, Marinetti, Apollinaire, Reverdy, Blas Cendrars, Francisco Picabia, Max Jacob, Tristan Tzara, expresionistas alemanes y otros. En 1919 se publican, además, homenajes a Walt Whitman con motivo de su centenario.

${ }_{13}$ Artículo copiado de un cuaderno de recortes de Cansinos-Asséns, sin datos bibliográficos.

${ }^{14}$ Op. cit., pp. 1175-1176. 
comenzaba su viraje hacia la nueva estética. Se trata del poema «Vates», dedicado a Apollinaire, perteneciente a Horizon carré y traducido al español por Cansinos-Asséns. Periódicamente siguen apareciendo en Grecia sus poemas, casi todos procedentes del libro Horizon carré ${ }^{15}$. Las leves variantes que ofrecen todos ellos con respecto a las ediciones más actuales pueden atribuirse a matices en la traducción. En cambio, nos brinda un caso de reelaboración el poema "Tarde» (en Grecia: 43, 1 junio 1920, p. 5) que encontramos muy transformado y ampliado en el libro Automne régulier, bajo el título «Llave de las estaciones» ( Clef des saisons»), en traducción de Teófilo Cid ${ }^{16}$.

TARDE

Yo poseo la llave del Otoño.

El pecho está lleno de alas amarillas

Y lloraré una tarde todos los arroyos

EL DIA MUERE EN TUS MEJILLAS

Ondula tus cabellos la música del arpa

El mundo viene a dormir bajo estas ramas

Un último recuerdo

Se ha posado en mi dedo

PAJARO VACIO

Todas las canciones cayeron en el río

$\mathrm{Y}$ aquello que guardaba en mi garganta,

Se alejó sobre el alba

Una comparación entre el poema transcrito y la versión definitiva que aparece en «Llave de las estaciones» muestra diferencias tipográficas y de tono emocional. En el primer poema hay síntesis y sugerencia; en el segundo, ampliación, mayor explicitación e irrupción de elementos futuristas que rompen el clima eglógico-cósmico.

Huidobro publica también en Cervantes, dirigida desde 1919 por Cansinos-Asséns. En enero de 1919 aparece «El día de la victoria», de Hallali; en julio del mismo año aparece completa «Ecuatorial» (pp. 1627). En agosto de 1919, otro poema de Hallali; en septiembre, «Torre Eiffel», en traducción de Cansinos-Asséns...

15 "Aeroplano», de H. C., bajo el título de «Novísima lírica francesa», y en versión española de G. de Torre, en Grecia, 20 (30 junio 1919), p. 9; "Arco voltaico» y «Cowboy», también de H. C., Grecia, 41 (29 febrero 1920), p. 9...

${ }^{16} \mathrm{Cf}$. Vicente Huidobro, Obras completas (ed. cit., vol. I), p. 327. Hay otra versión castellana de este poema, de Antonio Undurraga. 
Las revistas vinculadas con el ultraísmo comentan la obra de Huidobro. Es sin duda Cansinos quien lo promueve y elogia sin retaceos. En el número 1 de Cosmópolis (enero 1919), pp. 68-73, en los inicios del movimiento, aparece un artículo suyo: «Un gran poeta chileno, Vicente Huidobro y el creacionismo», el mismo que más tarde incluyó en La nueva literatura. En él señala la importancia de la visita del poeta chileno y su repercusión en el ambiente. Sintetiza los principios del creacionismo, transcribiendo párrafos del «pórtico» de Horizon carré (... «Hacer un poema como la naturaleza hace un árbol»). Reseña la evolución de Huidobro a partir de 1914 basándose en conversaciones con el poeta.

En Cosmópolis 5 (mayo 1919), pp. 72-80, el mismo autor publica «La nueva lírica». Allí se refiere a la concepción estética de Huidobro y algunos de sus recursos técnicos. Comenta las obras creacionistas: Horizon carré, Ecuatorial, Poemas árticos y Hallali, todo ello en un marco de historia literaria en el que alude a precedentes y contemporáneos vanguardistas, particularmente a Reverdy. El artículo es inteligente y penetrante. Señala los logros y aportes de las nuevas escuelas, pero predice también sus riesgos: «Expresar el mundo en imágenes absolutamente nuevas equivaldría a crearlo, y esto no es posible. El creacionismo absoluto tendría un pobre porvenir como escuela literaria; los poetas que siguieran esta norma estricta sólo podrían tener contados momentos de estado de gracia literaria» (p. 80) ${ }^{17}$.

Sin embargo, aún antes de que se agrietara la relación entre los ultraístas y el chileno, se insiste en establecer límites: «Huidobro fue, sobre todo, un documento personal, un evangelio vivo...; mas no se confunda este movimiento con ninguna escuela parcial de las que florecieron últimamente en Francia, ni con el creacionismo de Reverdy y Huidobro», dice Cansinos ${ }^{18}$.

${ }^{17}$ En otras revistas se hacen menciones más breves al poeta chileno. Por ejemplo, en Cervantes (agosto 1919), pp. 103-106, César Arroyo, en su artículo «Nueva poesía en América. La evolución de un gran poeta», hace una sintética historia del ultraísmo y señala la importancia de Huidobro en sus orígenes. Termina diciendo: «Y triángulo excelso, tres grandes artistas son, en los vastos dominios de la lengua castellana, los portaestandartes del arte nuevo: Rafael CansinosAsséns en España y Vicente Huidobro y José Juan Tablada en América» (p. 106). Manuel María Durand brinda otra admirativa adhesión a Huidobro en Ultra (Oviedo, 1 noviembre 1919), p. 3.

${ }_{18}$ R. Cansinos-Asséns, "Los poetas del Ultra», Cervantes (junio 1919), p. 85. Análoga afirmación hace José Rivas-Panedas en "Protesto en nombre de Ultra», Cervantes (septiembre 1919), pp. 142-148. 
Las revistas Cosmópolis y Alfar divulgan también las polémicas entre Huidobro y Guillermo de Torre, en torno al origen del creacionismo ${ }^{19}$.

\section{INFLuencia de Huidobro en los POETAS ESPAÑoles}

De los poetas influidos directamente por Huidobro, se destacan particularmente Juan Larrea y Gerardo Diego.

El mismo Diego testimonia la influencia que sobre él tuvo Huidobro: «Resulta hoy difícil de explicar a un muchacho que me lea lo que la poesía de Ecuatorial, de Horizon carré, de Poemas árticos o de Automne régulier suponía que el aprendiz de poeta que estrenaba ilusión y ambiciones en los días de la posguerra del 14. Por lo que a mí respecta, hubo en esta conversión dos momentos sucesivos. Uno, de presentimiento, de instintiva simpatía que me orientó inequívocamente hacia Huidobro y sus amigos cubistas, a la simple lectura de sus primeros libros, más sentidos que comprendidos desde mi rincón, avaramente copiados en acariciado cuaderno, para poder devolver puntualmente los raros ejemplares prestados. $Y$ otro, de entrega deslumbrada al contacto con la persona y con su ambiente, vivido día a día como antiguo vecino de la ciudad» ${ }^{20}$.

Pertenecen a la vertiente creacionista de Diego sus libros Imagen (1922) y Manual de espumas (1924). Esta influencia se prolonga en su Fábula de Equis y Zeda (1932), que reúne poemas de 1926 a 1929; en sus Poemas adrede (1932, 2. ${ }^{a}$ ed., 1943), con poemas escritos entre 1926 y 1941, y en su Biografía incompleta, libro dedicado a Vicente Huido-

19 En Cosmópolis, II, 20 (Madrid, agosto 1920), pp. 589-605, aparece «La poesía creacionista y la pugna entre sus progenitores», en donde G. de Torre da su versión acerca de la polémica Huidobro-Reverdy. Este artículo se continúa en otros aparecidos en los núms. 21 y. 22, de septiembre y octubre. El mismo autor publica «Los verdaderos antecedentes líricos del creacionismo en V. H.: Un genial e incógnito precursor uruguayo: Julio Herrera y Reissig», Alfar, 32 (La Coruña, septiembre 1923), pp. 14-17. Huidobro publica como réplica «Al fin se descubre mi maestro», suplemento castellano de la revista Création (París, febrero 1924), que apareció también en Alfar, 39 (abril 1924), pp. 21-25. En el mismo número aparece la contrarréplica de G. de Torre: «Rasgos polémicos. Réplica a V. H.», pp. 26-30.

${ }^{20}$ Gerardo Diego, op. cit., p. 1777. El ambiente al que se refiere Diego es el de los artistas vanguardistas de París, con quienes Huidobro estaba vinculado.

Son interesantes los testimonios del mismo Diego sobre sus obras «creacionistas». Cf. sus Versos escogidos (Madrid: Gredos, 1970), pp. 21-22, 27-28, 37-38... 
bro, con poemas que van desde 1925 hasta 1953, fecha de la primera edición y enriquecido por nuevas composiciones en la edición de 1967.

La devoción de Diego por Huidobro se mantiene, pues, a lo largo de los años, cuando su humor -o su inspiración - lo llevan a saltar del verso disciplinado, riguroso, ascético y reflexivo al vitalismo más anárquico que encauza su peculiar «creacionismo».

La relación personal y poética entre Juan Larrea y Vicente Huidobro en los años 1919 a 1926 ha sido ya clarificada en el artículo de Robert Gurney "Vicente Huidobro y Juan Larrea» ${ }^{21}$, de indudable valor documental, pues se basa en cartas de Larrea y en entrevistas mantenidas entre el historiador y el poeta.

Larrea relata en una carta al autor su primer contacto con la poesía de Huidobro: "Gerardo había venido de Madrid a Bilbao el 2 de mayo de 1919, ocasión en que me habló por primera vez de la existencia del ultraísmo, y supe de Grecia y de Vicente Huidobro. De éste recuerdo que me dio a conocer tres poemas que había transcrito de Poemas árticos. Tales noticias fueron para mí el fulminante que provocó una trayectoria para el resto de mis días» ${ }^{22}$.

En realidad, si bien se advierte la influencia del creacionismo en los poemas tempranos publicados por Larrea en Grecia y en Cervantes en 1919 y 1920, ya en esta etapa es evidente la pujanza de su personalidad. Ella se acentúa en los poemas que publicó en Favorables Paris Poema (París, 1926) y en Carmen (1927-1928).

Fue Juan Larrea un hito importante hacia el superrealismo en España ${ }^{23}$.

Es innegable que Huidobro influyó en la rica lírica de la generación del 27, ya en forma directa, ya a través de Diego o de Larrea, ya -de modo más indirecto pero también real- a través de los principios estéticos y de la atmósfera difundida por el ultraísmo ${ }^{24}$.

${ }^{21}$ Robert Edward Gurney, «Vicente Huidobro y Juan Larrea», Insula, número 337 (diciembre 1974), pp. 1 y 14.

22 Carta a R. E. Gurney, Córdoba (Argentina), 13 noviembre 1972, ibid., p. 1.

${ }^{23}$ Luis Cernuda le reconoce ese papel: «... no creo equivocarme al pensar que a él debieron Lorca y Alberti (y hasta Aleixandre) no sólo la noticia de una técnica literaria nueva para ellos, sino también un rumbo poético que sin la lectura de Larrea dudo que hubiesen hallado» (Estudios sobre poesía española contemporánea [Madrid: Cuadarrama, 1957], p. 194).

${ }^{24}$ Rafael Alberti, La arboleda perdida. Libros I y II de Memorias (Buenos Aires: Compañía Fabril Editora, 1959). 
Las contribuciones vanguardistas - fundidas con los aportes de la tradición literaria y con riquísimos y personalísimos talantes poéticosfructificarán en la excepcional generación del 27. Algunas de ellas son: el culto a la imagen y a sus múltiples posibilidades, la libertad para saltar los límites que impone la experiencia de la realidad y para ligar poéticamente elementos heterogéneos (ruptura de leyes espaciales, temporales, equiparación entre lo cósmico y lo humano, entre lo concreto y lo abstracto...), tendencia al juego, a la cabriola humorística e ingeniosa. En ciertos casos, una tipografía expresiva moderada y la supresión de los signos de puntuación, en orden a la ruptura de esquemas lógicos o convencionales.

Es interesante el caso de Rafael Alberti, pues la tarea de extraer de su obra temprana - con carácter de hipótesis- uno que otro rasgo vanguardista $y$, en particular, creacionista, se ve corroborada por sus propias declaraciones autobiográficas. Contamos para ello con dos fuentes: su libro de memorias $L a$ arboleda perdida y el prólogo al libro Poesías anteriores a $a$ Marinero en tierra» ${ }^{25}$, que difunde poemas recogidos por una sobrina del poeta, María Alberti.

Recuerda Alberti que escribió su primer poema en 1920, mientras en las calles se voceaba la revista Ultra. Allí conoció nombres de vanguardistas españoles y europeos ${ }^{26}$. Y afirma: «Ultra en seguida me conquistó» ${ }^{27}$.

Cuando caracteriza a sus poemas de 1922, señala explícitamente la influencia creacionista: «(Reverdy, Huidobro, Gerardo Diego)» ${ }^{28}$.

Además de los poemas recogidos en el libro que comentamos, pertenecen a este período algunos que aparecieron en Horizonte y Alfar y que Alberti recoge en su Poesía (1924-1967) (Madrid: Aguilar, 1972).

También otros integrantes de su generación debieron de conocer las revistas ultraístas y los libros de Huidobro.

Dámaso Alonso nos ha contado que Eugenio Montes, compañero de Facultad, le hizo conocer dos libros de Huidobro: Hallali y Tour Eiffel. Concurrió a algunas veladas ultraístas y en su biblioteca conserva revistas del movimiento, con subrayados y comentarios despectivos en los frecuentes casos de «bisutería» poética. Pero, a pesar de su actitud crí-

${ }^{25}$ Rafael Alberti, Poesías anteriores a «Marinero en tierra» (1920-1923) (Barcelona: Ediciones V. A., Col. «Insolites», 1969), incluidas con su prólogo en Canciones del Aniene $y$ otros versos y prosas (1967-1972) (Buenos Aires: Losada, 1972, 2. ${ }^{a}$ ed., 1977). Citaré por la 2. ${ }^{a}$ edición.

${ }^{20}$ Cf. La arboleda perdida, p. 148.

${ }^{27}$ Canciones del alto valle..., p. 194.

${ }^{28}$ Ibid., p. 195. 
tica, algo de las nuevas técnicas poéticas se filtró en sus Poemas puros, poemillas de la ciudad (1921).

Varios críticos han señalado la probable influencia del ultraísmo o del creacionismo en las técnicas metafóricas de Lorca. Lo cierto es que el poeta debió de conocer las revistas españolas de vanguardia, puesto que su nombre aparece junto con el de los ultraístas en publicaciones como Horizonte y Alfar, revistas que reflejan ya un período de decantación de las nuevas tendencias. (En el núm. 5 de Horizonte, 1923, aparece «Baladilla de los tres ríos»; en Alfar de los años 1924, 1925, aparecen otros poemas...).

Cerramos estas consideraciones con las palabras de Gerardo Diego: «Directamente, o a través de Larrea o algún otro discípulo directo, algo de lo mejor de Fernando Villalón, de Rafael Alberti, de Pablo Neruda, de Leopoldo Marechal, de Federico García Lorca, de otros poetas de Iengua española y de otras lenguas procede de fuente huidobriana» ${ }^{29}$.

Gloria Videla de Rivero

Universidad Nacional de Cuyo, Mendoza (Argentina).

${ }^{29}$ Gerardo Diego, Atenea, 295-296 (Santiago de Chile, enero-febrero 1950). 